\title{
Clinical Periodontal Parameters Associated with Diabetes Mellitus in Patients Attending a Private Dental Hospital in Chennai
}

\author{
Manali Deb Barma, S S Raj* and P Jayashri \\ Saveetha Dental College and Hospitals, Saveetha Institute of Medical and \\ Technical Sciences Saveetha University Chennai, India \\ Corresponding author email: samuelrajs.sdc@saveetha.com
}

\section{ABSTRACT}

Chronic periodontitis is an inflammatory condition that affects oral tissues surrounding the teeth, guided mainly by host immune inflammatory reaction. It is widely accepted that chronic periodontitis is one of the classical complications of diabetes. Therefore, the aim of the study was to assess the clinical periodontal parameters associated with diabetes mellitus. A hospital setting based study where case record data of total 80 study participants, 40 diabetics and 40 healthy participants were examined using Russell's Periodontal Index and CPITN Index and Descriptive statistics, Chi-square were used to analyse the data. The mean age of the study population was $56.1 \pm 13.4$ years. No statistical significance found between Russell's periodontal index scores and diabetes, CPITN scores and diabetes in our study population. From the results of the study, it can be concluded that, clinical periodontal parameters though slightly severe among diabetic patients, no statistical significance was found when compared with the healthy patients. The periodontal parameters showed a moderate severity among diabetic patients compared to non-diabetic patients, even though no statistical difference was observed. As dental health professionals, our focus should be on improvising the oral hygiene of the diabetic patients to limit the progression of the disease.

\section{KEY WORDS: BLEEDING ON PROBING; BONE LOSS; DIABETES; PERIODONTAL POCKET; RUSSELL'S PERIODONTAL INDEX.}

\section{INTRODUCTION}

Periodontal disease is a chronic inflammatory disease of periodontium and is characterized by periodontal ligament loss and destruction of surrounding alveolar bone. It is the main cause of tooth loss among adults and is responsible for the global burden of disease. According to the National Oral Health Survey, the prevalence of periodontitis in India was $57 \%, 67.7 \%, 89.6 \%, 79.9 \%$, in the age groups $12,15,35$ 44, $65-74$ years respectively. Periodontitis leads to negative impacts and poor oral health related quality of life. Among various risk factors, diabetes has been confirmed as a major risk factor. Many studies have demonstrated the influence of diabetes on oral health conditions. Prevalence of severe

Biosc Biotech Res Comm P-ISSN: 0974-6455 E-ISSN: 2321-4007

\section{crossef}

Identifiers and Pagination

Year: 2021 Vol: 14 No (10) Special Issue

Pages: 83-89

This is an open access article under Creative

Commons License Attribn 4.0 Intl (CC-BY).

DOI: $h t t p: / / d x . d o i . o r g / 10.21786 / b b r c / 14.10 .144$ periodontitis in diabetics as compared to non-diabetics has been found to be $59.6 \%$ and $39 \%$. The explanation for this was stated as, chronic hyperglycemia increases the expression of toll like receptors and pro inflammatory cytokines in periodontal tissue, thus augmenting periodontal inflammation (Kinane, 2001; Esa et al., 2001; Mathur et al., 2004; Al-Harthi et al., 2013; Huang et al., 2016; Nazir, 2017; Pavithra and Jayashri, 2019; Samuel et al., 2020).

Periodontal disease other than being the sixth complication of diabetes, also leads to an array of other oral health related problems such as heavy plaque accumulation leading to increased microbial concentration causing gingival diseases and dental caries, salivary gland dysfunction, may give rise to lesions in oral cavity which may cause nutritional problems (Saini et al., Saini and Sugandha, 2011; Prabakar et al., 2018b; Mebin et al., 2020; Neralla et al., 2019; Prabakar et al., 2016; Prabakar et al., 2018a; Prabakar et al., 2018; Mohapatra et al., 2019; Pratha and Prabakar, 2019; Pavithra and Jayashri, 2019; Samuel et al., 2020).

Another main factor influencing the severity of periodontitis is smoking where studies have shown moderate smokers

\section{Article Information}

Received: $09^{\text {th }}$ Aug 2021

Accepted after revision: $24^{\text {th }}$ Oct 2021 
have a 1.32 times higher risk of periodontal disease and heavy smokers have a 2.33 times higher risk. Also, there have been studies showing association of fluorosis with periodontal diseases which states fluoride could play a role as an environmental factor in causing periodontitis through its effect on hard and soft tissues of the periodontium. Therefore, it can be concluded that periodontal disease also depends on a number of factors (Vandana, 2014; Jang et al., 2016; Kumar and Preethi, 2017; Kumar and Vijayalakshmi, 2017; Khatri et al., 2019; Leelavathi and Others, 2019; Sathish and Karthick, 2020).

There are studies that report abnormal collagen metabolism, abnormal polymorphonuclear cell (PMN) function and altered microbial flora are found in close association with severity of periodontitis in diabetic patients, whereas other studies suggest there is no relationship between diabetes and periodontal disease there is no relationship between diabetes and periodontal disease and when these two conditions exist together, it is a coincidence rather than a specific cause and effect relationship. There is a difference of opinion regarding the relationship between periodontitis and diabetes, this study was conducted to assess clinical periodontal parameters associated with diabetes mellitus among the adult population visiting a private dental college in Chennai (Bernick et al., 1975; Ervasti et al., 1985; Hayden and Buckley, 1989; Grossi et al., 1996; Pavithra and Jayashri, 2019; Samuel et al., 2020).

Previously our team has a rich experience in working on various research projects across multiple disciplines (Gheena and Ezhilarasan, 2019; Ke et al., 2019; Malli Sureshbabu et al., 2019; Mehta et al., 2019; Samuel et al., 2019; Sharma et al., 2019; Varghese et al., 2019; Venu et al., 2019; Vignesh et al., 2019; Jain et al., 2019; Jose et al., 2020; Krishnaswamy et al., 2020; Muthukrishnan et al., 2020; Samuel et al., 2020; Sathish and Karthick, 2020). Now the growing trend in this area motivated us to pursue this project.

\section{MATERIAL AND METHODS}

A retrospective study was conducted among patients reporting to the OPD of Saveetha Dental College with periodontal problems. The study was conducted between August 2019 - January 2020. Simple Random Sampling was carried out to select a total case record of 80 patients, out of which 40 were diabetic and 40 were healthy patients. Prior to the start of the study, ethical approval (SDC/SIHEC/2020/DIASDATA/0619-0320) was obtained from Scientific Review Board, Saveetha Dental College, SIMATS University. Data consisting of age, disease status, periodontal health status was retrieved from records of patients who visited the dental college. The periodontal status was quantified using Russell's Periodontal Index and CPITN Index. The oral examination was done using a mouth mirror, William's probe and WHO probe under bright light and dental chair by trained examiners. To measure CPITN Index, the WHO probe with working tip of $0.5 \mathrm{~mm}$ in diameter and markings at $3.5 \mathrm{~mm}, 5.5 \mathrm{~mm}$, $8.5 \mathrm{~mm}$ and $11.5 \mathrm{~mm}$ was used as it reduces the chances of false measurement of the pocket depth.
The index teeth $17 / 16,11,26 / 27,37 / 36,21,46 / 47$ were examined and a code was given to each extant, but only the highest code was recorded among the examined teeth in individual sextant. After evaluating the periodontal status, Treatment Needs (TN) for each subject was categorized on the basis of highest code recorded during the examination of all sextants in the subject. While recording Russell's Periodontal Index, all teeth present were subjected to examination. Scoring values of 1, 2, 4, 6, 8 were given and cumulative score was obtained to elucidate the final periodontal status score and patients were categorized based on that. The findings were recorded according to the criteria's provided by the author and entered into the digital system.

Statistical Analysis: Data was analyzed using SPSS Version 23.0. Descriptive statistics, Chi square were used to analyse the parameters among the two groups. Statistical significance was set at $\mathrm{p}<0.05$.

\section{RESULTS AND DISCUSSION}

The study consists of case records of 80 participants out of which $52.50 \%$ were males and $47.50 \%$ were females as seen in Figure 1. The mean age of the participants was $56.1 \pm 13.4$ overall, for diabetics it was $61.4 \pm 8.2$ and for healthy patients, $50.8 \pm 15.4$ (Table 1) Figure 2 shows the distribution of participants based on Russell's Periodontal Score, $48.75 \%$ had "Established Destructive Periodontal Tissue", followed by $32.50 \%$ experiencing "Beginning of Destructive Periodontal Tissue", out of the total study population, $10.0 \%$ has "Terminal Disease", $7.50 \%$ has "Simple Gingivitis" and 1.25\% has "Clinically Normal Supportive Tissue".

Figure 1: The pie chart represents the distribution of study population based on gender, where $67.69 \%$ were males (denoted by colour blue) and $32.31 \%$ were females (denoted by colour red), thus showing a male predilection in the study population.

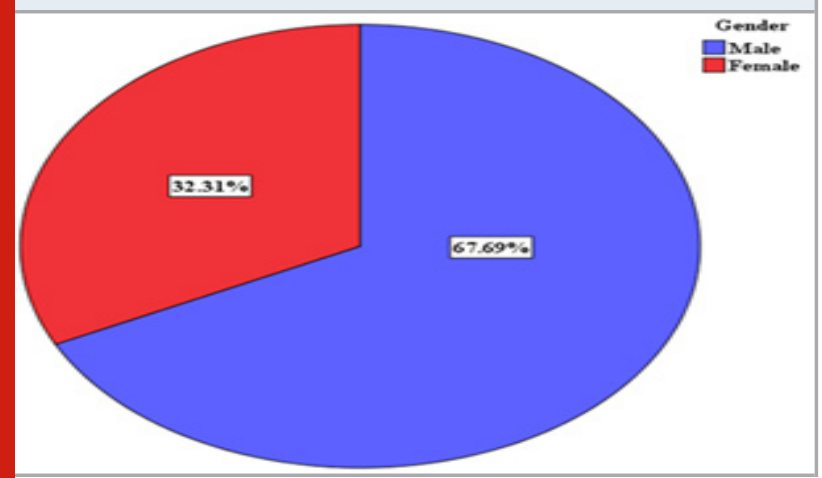

The participants were also categorised based on their CPITN Score, which revealed $61.25 \%$ had Supra/Subgingival calculus, indicating need for professional cleaning of teeth and removal of plaque retentive factors, $27.50 \%$ had periodontal pockets with $4-5 \mathrm{~mm}$ depth indicating treatment need for scaling and root planing, $6.25 \%$ of the participants had gingival bleeding on probing, indicating a need for improving their personal hygiene, whereas the $5.0 \%$ of 
participants who had periodontal pocket depth more than 6 mm depth needed to undergo complex procedures involving deep scaling, root planing and further surgical treatments (Figure 3). The comparison of Russell's Periodontal score among diabetics and non-diabetics did not produce a statistically significant value $(p=0.3)$ even though the severity of periodontal disease was higher in diabetic patients as shown in Figure 4. Similarly, no statistical significance was seen among the two groups in terms of CPITN score $(p=0.6)$ as given in Figure 5.

Table 1. Mean Age of study participants

\begin{tabular}{|l|c|c|c|}
\hline Variable & $\mathbf{N}$ & Mean & Standard Deviation \\
\hline Overall & 80 & 56.1 years & 13.4 \\
\hline Diabetic & 40 & 50.8 years & 15.4 \\
\hline Non-diabetic & 40 & 61.4 years & 8.2 \\
\hline
\end{tabular}

Figure 2: The bar graph represents the distribution of the study population based on Russell's periodontal score. $X$ axis represents Russell's periodontal score and $Y$ axis represents the distribution of study participants based on Russell's periodontal score. Among the study population, $\mathbf{4 8 . 8 \%}$ of all participants had established destructive periodontal tissue.

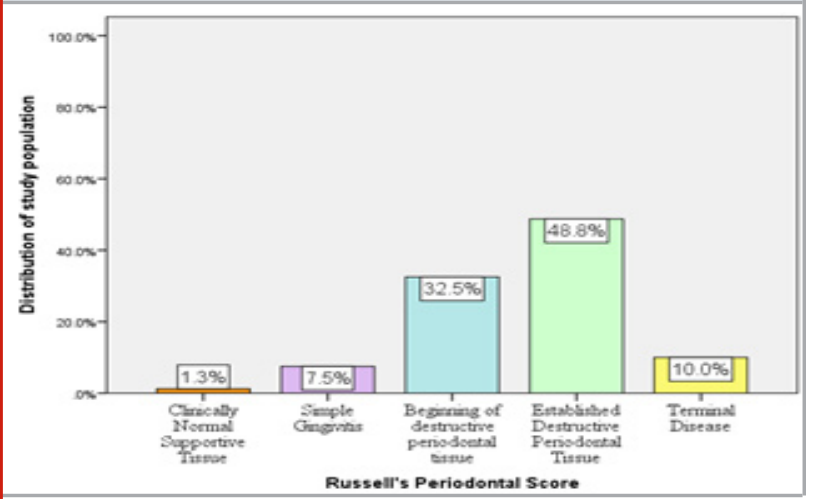

The current study was based on the alternate hypothesis that periodontal parameters are worse in diabetic patients than in non-diabetic patients. The results of this study support the hypothesis, however no statistically significant difference was observed in Russell's periodontal scoring and CPITN scoring when periodontal health of diabetic patients was compared to periodontal health of non-diabetic patients. One possible explanation for this could be that risk factors for periodontitis includes genetic, ethnicity, advancing age, smoking and not just presence or absence of systemic disease. There are reports of statistically significant relationship between the duration of hyperglycemia and severity of periodontal inflammation. In the current study, the duration of diabetes among the diabetic patients was approximately 3-4 years, therefore it could have resulted in the limited effect of hyperglycemia. Similar findings were reported in studies conducted by Shammari et al., Mohammed et al (Goldin et al., 2006; Al-Shammari et al.,
2006; Javed et al., 2014; Alasqah et al., 2018; Vijayashree, 2019; Mathew et al., 2020).

Figure 3: represents the distribution of CPITN scores among the study population. $X$ axis represents the CPITN score and $\mathrm{Y}$ axis represents the distribution of the study population based on CPITN score. Among the study population, the majority of the participants $(61.3 \%)$ had supra/subgingival calculus.

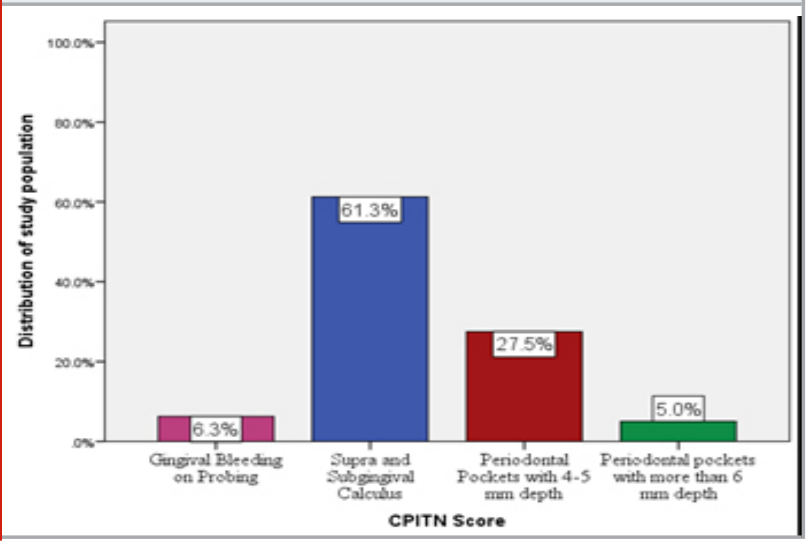

Figure 4: Represents the association between the diabetics, non-diabetics and Russell's Periodontal score. $X$ axis represents the disease status, i.e diabetics and non- diabetics and $\mathrm{Y}$ axis represents the distribution of study population based on Russell's periodontal score. Chi square test was used and prevalence of destructive periodontal tissue was more in diabetics $(26.2 \%)$ than in non-diabetics $(22.5 \%)$, however no statistical significance was observed. $\chi 2=4.051$, df $=4$, $p$ value $=0.3$; hence, statistically not significant.

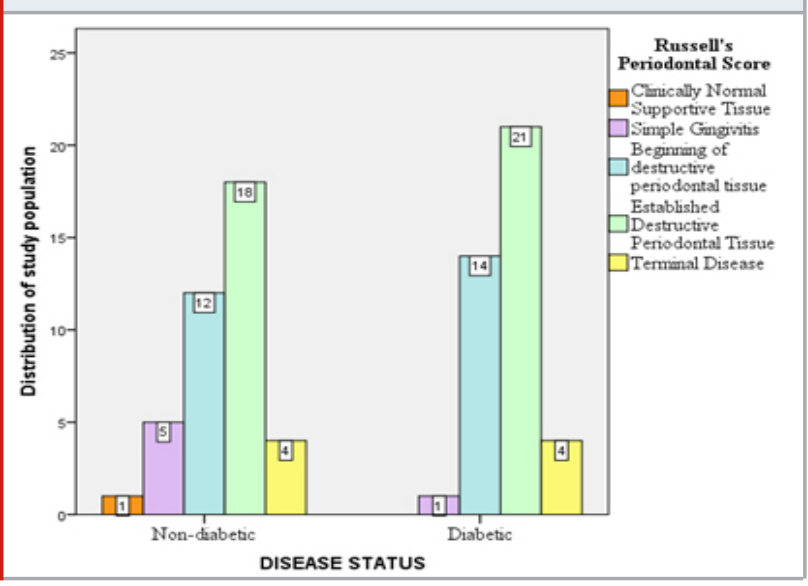

However, studies have also reported statistical significance between Russell's periodontal score and duration of diabetes. The present study shows majority of the participants $(61.2 \%)$ had supra/subgingival calculus, which coincides with the findings of other studies where removal of calculus was intended for majority of the study population, in a study conducted by Dan et al among patients of Rheumatoid arthritis, a study done among Intellectually Disabled patients contrasting results were found in other studies. The distribution of participants with pocket depth 
more than $6 \mathrm{~mm}$ was around $5 \%$, similar to other study by Dan et al., which could be explained by the fact that the less severity of periodontitis among this set of study participants could be attributed to the age group of the participants as, the present study had participants below 60 years of age, the studies with opposing results had participants over 65 years of age (Bretz et al., 2005; Kim et al., 2013; PipereaSianu et al., 2013; Piperea-Sianu et al., 2013; Diab et al., 2017; Vijayashree, 2019; Mathew et al., 2020).

Figure 5: Represents the association between diabetics, non-diabetics and CPITN score. $X$ axis represents disease status and $\mathrm{Y}$ axis represents the distribution of study population based on CPITN score. Chi square test was used, and periodontal pocket depths were more severe in diabetics $(15.0 \%)$ than in non-diabetics $(12.5 \%)$, however no statistical significance was observed. $\chi 2$ value $=1.565, \mathrm{df}$ $=3$, $p$ value $=0.6$; hence, statistically not significant

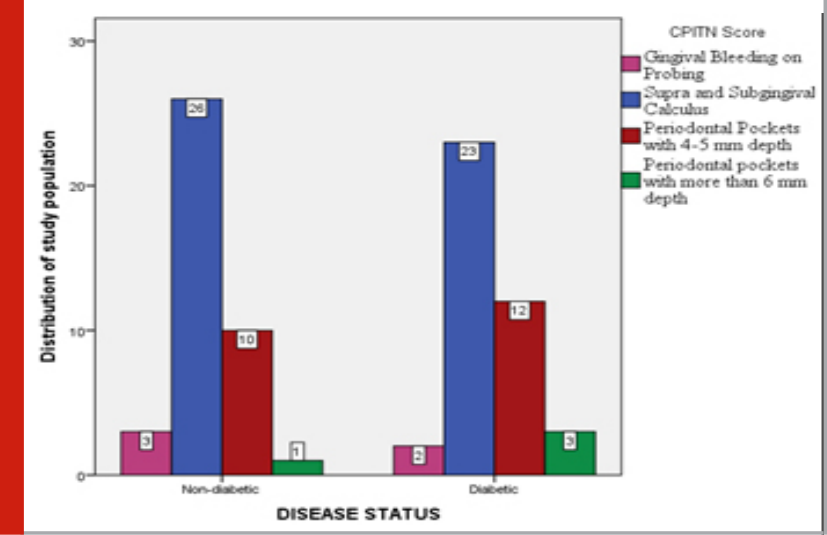

Periodontal conditions begin to undergo a faster destruction among diabetic patients aged 35 years and above as reported by Bacic et al. The odds of having severe periodontitis according to Russell's Periodontal scoring was slightly more in diabetic patients as to non-diabetics, as also seen in previous studies. As clinicians and public health professionals, it is necessary to evaluate the progression of periodontal disease among diabetic patients' early diagnosis and treatment could result in a better oral health related quality of life and decrease the burden of disease (Bacić et al., 1988; Brown et al., 1990; Torrungruang et al., 2005; Kannan et al., 2017).

Limitations: The study was conducted in a hospital setting, so patients seeking treatment have only been included, also the sample size being small, the results cannot be generalised. Our institution is passionate about high quality evidence based research and has excelled in various fields (Pc et al., 2018; Ramesh et al., 2018; Ezhilarasan et al., 2019; Ramadurai et al., 2019; Sridharan et al., 2019; Vijayashree, 2019; Mathew et al., 2020). We hope this study adds to this rich legacy.

\section{CONCLUSION}

The periodontal parameters showed a moderate severity among diabetic patients compared to non-diabetic patients, even though no statistical difference was observed. As dental health professionals, our focus should be on improvising the oral hygiene of the diabetic patients to limit the progression of the disease.

\section{REFERENCES}

Alasqah, M. et al. (2018). Periodontal parameters in prediabetes, type 2 diabetes mellitus, and non-diabetic patients. Brazilian oral research, 32, p. e81. doi: 10.1590/1807-3107bor-2018.vol32.0081.

Al-Harthi, L. S. et al. (2013). The impact of periodontitis on oral health-related quality of life: a review of the evidence from observational studies. Australian dental journal, 58(3), pp. 274-7; quiz 384. doi: 10.1111/adj.12076.

Al-Shammari, K. F. et al. (2006). Association of periodontal disease severity with diabetes duration and diabetic complications in patients with type 1 diabetes mellitus. Journal of the International Academy of Periodontology, 8(4), pp. 109-114. Available at: https://www.ncbi.nlm.nih. gov/pubmed/17042166.

Bacić, M., Plancak, D. and Granić, M. (1988). CPITN assessment of periodontal disease in diabetic patients. Journal of periodontology, 59(12), pp. 816-822. doi: 10.1902/jop.1988.59.12.816.

Bernick, S. M. et al. (1975). Dental disease in children with diabetes mellitus. Journal of periodontology, 46(4), pp. 241-245. doi: 10.1902/jop.1975.46.4.241.

Bretz, W. A. et al. (2005). Systemic inflammatory markers, periodontal diseases, and periodontal infections in an elderly population. Journal of the American Geriatrics Society, 53(9), pp. 1532-1537. doi: 10.1111/j.15325415.2005. 53468.x.

Brown, L. J., Oliver, R. C. and Loe, H. (1990). Evaluating periodontal status of US employed adults. Journal of the American Dental Association, 121(2), pp. 226-232. doi: 10.14219/jada.archive.1990.0252.

Diab, H. A., Hamadeh, G. N. and Ayoub, F. (2017). Evaluation of Periodontal Status and Treatment Needs of Institutionalized Intellectually Disabled Individuals in Lebanon. Journal of International Society of Preventive \& Community Dentistry, 7(3), pp. 76-83. doi: 10.4103/ jispcd.JISPCD_120_17.

Ervasti, T. et al. (1985). Relation between control of diabetes and gingival bleeding. Journal of periodontology, 56(3), pp. 154-157. doi: 10.1902/jop.1985.56.3.154.

Esa, R., Razak, I. A. and Allister, J. H. (2001). Epidemiology of malocclusion and orthodontic treatment need of 12-13year-old Malaysian schoolchildren. Community dental health, 18(1), pp. 31-36. Available at: https://www.ncbi. nlm.nih.gov/pubmed/11421403.

Ezhilarasan, D., Apoorva, V. S. and Ashok Vardhan, N. (2019). Syzygium cumini extract induced reactive oxygen species-mediated apoptosis in human oral squamous 
carcinoma cells. Journal of oral pathology \& medicine: official publication of the International Association of Oral Pathologists and the American Academy of Oral Pathology, 48(2), pp. 115-121. doi: 10.1111/jop.12806. Gheena, S. and Ezhilarasan, D. (2019). Syringic acid triggers reactive oxygen species-mediated cytotoxicity in HepG2 cells. Human \& experimental toxicology, 38(6), pp. 694-702. doi: 10.1177/0960327119839173.

Goldin, A. et al. (2006). Advanced glycation end products: sparking the development of diabetic vascular injury. Circulation, 114(6), pp. 597-605. doi: 10.1161/ CIRCULATIONAHA.106.621854.

Grossi, S. G. et al. (1996). Response to Periodontal Therapy in Diabetics and Smokers. Journal of periodontology, 67 Suppl 10S, pp. 1094-1102. doi: 10.1902/jop.1996.67.10s.1094.

Hayden, P. and Buckley, L. A. (1989). Diabetes mellitus and periodontal disease in an Irish population. Journal of periodontal research, 24(5), pp. 298-302. doi: 10.1111/ j.1600-0765. 1989.tb00873.x.

Huang, Y. et al. (2016). Prediabetes Enhances Periodontal Inflammation Consistent With Activation of Toll-Like Receptor--Mediated Nuclear Factor- $\kappa B$ Pathway in Rats. Journal of periodontology, 87(5), pp. e64-e74. Available at: https://aap.onlinelibrary.wiley.com/doi/abs/10.1902/ jop.2015.150522.

Jain V. S. et al. (2019). Evaluation of Three-Dimensional Changes in Pharyngeal Airway Following Isolated Lefort One Osteotomy for the Correction of Vertical Maxillary Excess: A Prospective Study. Journal of maxillofacial and oral surgery, 18(1), pp. 139-146. doi: 10.1007/s12663018-1113-4.

Jang, A.-Y. et al. (2016). Association between Smoking and Periodontal Disease in Korean Adults: The Fifth Korea National Health and Nutrition Examination Survey (2010 and 2012). Korean journal of family medicine, 37(2), pp. 117-122. doi: 10.4082/kjfm.2016.37.2.117.

Javed, F. et al. (2014). Effect of glycemic control on self-perceived oral health, periodontal parameters, and alveolar bone loss among patients with prediabetes. Journal of periodontology, 85(2), pp. 234-241. Available at: https://onlinelibrary.wiley.com/doi/abs/10.1902/ jop.2013.130008.

Jose, J., Ajitha and Subbaiyan, H. (2020). Different treatment modalities followed by dental practitioners for Ellis class 2 fracture - A questionnaire-based survey. The open dentistry journal, 14(1), pp. 59-65. doi: 10.2174/1874210602014010059.

Kannan, S. S. D. et al. (2017). Awareness and attitude towards mass disaster and its management among house surgeons in a dental college and hospital in chennai, india. Wit Press, pp. 121-129. doi: 10.2495/DMAN170121.

Ke, Y. et al. (2019). Photosynthesized gold nanoparticles from Catharanthus roseus induces caspase-mediated apoptosis in cervical cancer cells (HeLa). Artificial cells, nanomedicine, and biotechnology, 47(1), pp. 1938-1946. doi: 10.1080/21691401.2019.1614017.

Khatri, S. G. et al. (2019). Retention of moisture-tolerant fluoride-releasing sealant and amorphous calcium phosphate-containing sealant in 6-9-year-old children: A randomized controlled trial. Journal of the Indian Society of Pedodontics and Preventive Dentistry, 37(1), pp. 92-98. doi: 10.4103/JISPPD.JISPPD_173_18.

Kim, E.-K. et al. (2013). Association between diabetesrelated factors and clinical periodontal parameters in type-2 diabetes mellitus. BMC oral health, 13, p. 64. doi: 10.1186/1472-6831-13-64.

Kinane, D. F. (2001). Causation and pathogenesis of periodontal disease. Periodontology 2000, 25, pp. 8-20. doi: 10.1034/j.1600-0757.2001. 22250102.x.

Krishnaswamy, H. et al. (2020). Investigation of air conditioning temperature variation by modifying the structure of passenger car using computational fluid dynamics. Thermal science, 24(1 Part B), pp. 495-498. doi: 10.2298/tsci190409397k.

Kumar, R. P. and Preethi, R. (2017). Assessment of Water Quality and Pollution of Porur, Chembarambakkam and Puzhal Lake. Research Journal of Pharmacy and Technology, 10(7), pp. 2157-2159. Available at:

Kumar, R. P. and Vijayalakshmi, B. (2017). Assessment of fluoride concentration in ground water in Madurai district, Tamil Nadu, India. Research Journal of Pharmacy and Technology, 10(1), pp. 309-310. Available at: http://www. indianjournals.com/ijor.aspx?target=ijor:rjpt\&volume $=10$ \&issue $=1$ \&article $=063$.

Leelavathi, L. and Others (2019). Nicotine Replacement Therapy for Smoking Cessation-An Overview. Indian Journal of Public Health Research \& Development, 10(11). Available at:

Malli Sureshbabu, N. et al. (2019). Concentrated Growth Factors as an Ingenious Biomaterial in Regeneration of Bony Defects after Periapical Surgery: A Report of Two Cases. Case reports in dentistry, 2019, p. 7046203. doi: 10.1155/2019/7046203.

Mathew, M. G. et al. (2020). Evaluation of adhesion of Streptococcus mutans, plaque accumulation on zirconia and stainless steel crowns, and surrounding gingival inflammation in primary. Clinical oral investigations. Available at: https://link.springer.com/article/10.1007/ s00784-020-03204-9.

Mathur, B. et al. (2004). National oral health survey and flouride mapping 2002-2003. India. New Delhi: Dental Council of India.

Mehta, M. et al. (2019). Oligonucleotide therapy: An emerging focus area for drug delivery in chronic inflammatory respiratory diseases. Chemico-biological 
interactions, 308, pp. 206-215. doi: 10.1016/j. cbi.2019.05.028.

Mohapatra, S. et al. (2019). Assessment of Microhardness of Enamel Carious Like Lesions After Treatment with Nova Min, Bio Min and Remin Pro Containing Toothpastes: An in Vitro Study. Indian Journal of Public Health Research \& Development, 10(10), pp. 375-380. Available at: http:// www.indianjournals.com/ijor.aspx?target=ijor:ijphrd\&vo lume $=10$ \&issue $=10$ \&article $=076$.

Muthukrishnan, S. et al. (2020). Support vector machine for modelling and simulation of heat exchangers. Thermal science, 24(1 Part B), pp. 499-503. doi: 10.2298/ tsci190419398m.

Nazir, M. A. (2017). Prevalence of periodontal disease, its association with systemic diseases and prevention. International journal of health sciences, 11(2), pp. 72-80. Available at: https://www.ncbi.nlm.nih.gov/ pubmed/28539867.

Neralla, M. et al. (2019). Role of nutrition in rehabilitation of patients following surgery for oral squamous cell carcinoma. International Journal of Research in Pharmaceutical Sciences, 10(4), pp. 3197-3203. doi: 10.26452/ijrps. v10i4.1622.

Pavithra, R. P. and Jayashri, P. (2019). Influence of Naturally Occurring Phytochemicals on Oral Health. Research Journal of Pharmacy and Technology, 12(8), pp. 3979-3983.

Pc, J., Marimuthu, T. and Devadoss, P. (2018). Prevalence and measurement of anterior loop of the mandibular canal using CBCT: A cross sectional study. Clinical implant dentistry and related research. Available at: https:// europepmc.org/article/med/29624863.

Piperea-Sianu, D. et al. (2013). Periodontal health status evaluation using cpitn score, in a group of patients with rheumatoid arthritis. Hospital; la revista interamericana de hospitales, 2014.

Prabakar, J., John, J. and Srisakthi, D. (2016). Prevalence of dental caries and treatment needs among school going children of Chandigarh. Indian journal of dental research: official publication of Indian Society for Dental Research, 27(5), pp. 547-552. doi: 10.4103/0970-9290.195683.

Prabakar, J., John, J., Arumugham, I. M., Kumar, R. P. and Sakthi, D. S. (2018a). Comparative Evaluation of the Viscosity and Length of Resin Tags of Conventional and Hydrophilic Pit and Fissure Sealants on Permanent Molars: An In vitro Study. Contemporary clinical dentistry, 9(3), pp. 388-394. doi: 10.4103/ccd.ccd_131_18.

Prabakar, J., John, J., Arumugham, I. M., Kumar, R. P. and Sakthi, D. S. (2018b). Comparing the Effectiveness of Probiotic, Green Tea, and Chlorhexidine- and Fluoridecontaining Dentifrices on Oral Microbial Flora: A Double-blind, Randomized Clinical Trial. Contemporary clinical dentistry, 9(4), pp. 560-569. doi: 10.4103/ccd. ccd_659_18.

Prabakar, J., John, J., Arumugham, I. M., Kumar, R. P. and Srisakthi, D. (2018). Comparative Evaluation of Retention, Cariostatic Effect and Discoloration of Conventional and Hydrophilic Sealants - A Single Blinded Randomized Split Mouth Clinical Trial. Contemporary clinical dentistry, 9(Suppl 2), pp. S233-S239. doi: 10.4103/ccd. ccd_132_18.

Pratha, A. A. and Prabakar, J. (2019). Comparing the effect of Carbonated and energy drinks on salivary pH-In Vivo Randomized Controlled Trial. Research Journal of Pharmacy and Technology, 12(10), pp. 4699-4702.

Ramadurai, N. et al. (2019). Effectiveness of $2 \%$ Articaine as an anesthetic agent in children: randomized controlled trial. Clinical oral investigations, 23(9), pp. 3543-3550. doi: 10.1007/s00784-018-2775-5.

Ramesh, A. et al. (2018). Comparative estimation of sulfiredoxin levels between chronic periodontitis and healthy patients - A case-control study. Journal of periodontology, 89(10), pp. 1241-1248. doi: 10.1002/ JPER.17-0445.

Saini, R., Saini, S. and Sugandha, R. (2011). Periodontal disease: The sixth complication of diabetes. Journal of family \& community medicine, 18(1), p. 31. doi: 10.4103/1319-1683.78636.

Samuel, M. S. et al. (2019). Efficient removal of Chromium (VI) from aqueous solution using chitosan grafted graphene oxide (CS-GO) nanocomposite. International journal of biological macromolecules, 121, pp. 285-292. doi: 10.1016/j.ijbiomac.2018.09.170.

Samuel, S. R., Acharya, S. and Rao, J. C. (2020) 'School Interventions-based Prevention of Early-Childhood Caries among 3-5-year-old children from very low socioeconomic status: Two-year randomized trial', Journal of public health dentistry, 80(1), pp. 51-60. doi: 10.1111/jphd.12348.

Sathish, T. and Karthick, S. (2020). Wear behaviour analysis on aluminium alloy 7050 with reinforced $\mathrm{SiC}$ through taguchi approach. Journal of Japan Research Institute for Advanced Copper-Base Materials and Technologies, 9(3), pp. 3481-3487. doi: 10.1016/j.jmrt.2020.01.085.

Sharma, P. et al. (2019). Emerging trends in the novel drug delivery approaches for the treatment of lung cancer. Chemico-biological interactions, 309, p. 108720. doi: 10.1016/j.cbi.2019.06.033.

Sridharan, G. et al. (2019). Evaluation of salivary metabolomics in oral leukoplakia and oral squamous cell carcinoma. Journal of oral pathology \& medicine: official publication of the International Association of Oral Pathologists and the American Academy of Oral Pathology, 48(4), pp. 299-306. doi: 10.1111/jop.12835. Torrungruang, K. et al. (2005). Risk indicators of periodontal disease in older Thai adults. Journal of periodontology, 76(4), pp. 558-565. doi: 10.1902/ 
jop.2005.76.4.558

Vandana, K. L. (2014). Fluorosis and periodontium: A report of our institutional studies. Journal of the International Clinical Dental Research Organization, 6(1), p. 7. doi: 10.4103/2231-0754.139084.

Varghese, S. S., Ramesh, A. and Veeraiyan, D. N. (2019). Blended Module-Based Teaching in Biostatistics and Research Methodology: A Retrospective Study with Postgraduate Dental Students. Journal of dental education, 83(4), pp. 445-450. doi: 10.21815/JDE.019.054.

Venu, H., Raju, V. D. and Subramani, L. (2019). Combined effect of influence of nano additives, combustion chamber geometry and injection timing in a DI diesel engine fuelled with ternary (diesel-biodiesel-ethanol) blends. Energy, 174, pp. 386-406. doi: 10.1016/j.energy.2019.02.163.
Venu, H., Subramani, L. and Raju, V. D. (2019). Emission reduction in a DI diesel engine using exhaust gas recirculation (EGR) of palm biodiesel blended with $\mathrm{TiO} 2$ nano additives. Renewable Energy, 140, pp. 245-263. doi: 10.1016/j.renene.2019.03.078.

Vignesh, R. et al. (2019). Management of Complicated Crown-Root Fracture by Extra-Oral Fragment Reattachment and Intentional Reimplantation with 2 Years Review. Contemporary clinical dentistry, 10(2), pp. 397-401. doi: 10.4103/ccd.ccd_671_18.

Vijayashree P. J. (2019). In silico validation of the non-antibiotic drugs acetaminophen and ibuprofen as antibacterial agents against red complex pathogens. Journal of periodontology, 90(12), pp. 1441-1448. doi: 10.1002/JPER.18-0673. 